\title{
Acromioclavicular third degree dislocation: surgical treatment in acute cases
}

Angelo De Carli, Riccardo Maria Lanzetti, Alessandro Ciompi, Domenico Lupariello, Pierpaolo Rota and Andrea Ferretti

\begin{abstract}
Background: The management of acute Rockwood type III acromioclavicular joint (ACJ) dislocation remains controversial, and the debate about whether patients should be conservatively or surgically treated continues. This study aims to compare conservative and surgical treatment of acute type III ACJ injuries in active sport participants ( $<35$ years of age) by analysing clinical and radiological results after a minimum of 24 months follow-up.

Methods: The records of 72 patients with acute type III ACJ dislocations who were treated from January 2006 to December 2011 were retrospectively evaluated. Patients were categorised into two groups. group A included 25 patients treated conservatively, and group B included 30 patients treated surgically with the TightRope ${ }^{\mathrm{TM}}$ system. Seventeen patients were lost to follow-up.

All patients were evaluated at final follow-up with these clinical scores: Constant, University of California Los Angeles scale (UCLA), American Shoulder and Elbow Surgeons Scale (ASES) and Acromioclavicular Joint Instability (ACJI) and with a subjective evaluation of the patient satisfaction, aesthetic results and shoulder function. The distance between the acromion and clavicle and between the coracoid process and clavicle were evaluated radiographically and compared with preoperative values. $\Delta$, the difference in mm between the distance at the final follow-up and at T0 in the injured shoulder, and $a$, the side-to-side difference in $\mathrm{mm}$ at follow-up, were calculated. Heterotopic ossification and postoperative osteolysis were evaluated in both groups.
\end{abstract}

Results: There were no major intraoperative complications in the surgical group. The subjective parameters significantly differed between the two groups. Constant, ASES and UCLA scores were similar in both groups $(P>0.05)$, whereas AC results favoured the surgical group (group $A, 72.4$; group $B, 87.9 ; P<0.05$ ). All measurements of radiographic evaluation were significantly reduced in the surgical group compared with the conservative group. In group A, we detected calcifications in $30 \%$ of patients; in group B we detected two cases of moderate osteolysis and calcifications in $70 \%$ of patients.

Conclusion: Although better subjective and radiographic results were achieved in surgically treated patients, traditional objective scores did not show significant differences between the two groups. Our results cannot support routine use of surgery to treat type III ACJ dislocations.

Keyword: Acromioclavicular joint dislocation, TightRope, Rockwood type III dislocation, Shoulder

\section{Background}

Acromioclavicular joint dislocation is one of the most common shoulder injuries treated in general orthopaedic practice. It is the most frequent shoulder injury among contact sport participants [1]. Acromioclavicular dislocations occur in $41 \%$ of collegiate football players and in

\footnotetext{
* Correspondence: angelo.decarli@gmail.com

Orthopaedic Unit and "Kirk Kilgour" Sports Injury Centre, S. Andrea Hospital, University of Rome "La Sapienza", Italy, Via di Grottarossa 1035, 00189 Rome,
} Italy

\section{Biomed Central}

$40 \%$ of (US) National Football League quarterbacks [2,3]. These dislocations are more common in men than in women, at a five to one ratio [4], perhaps because men are more likely to practise contact sports than women are.

There is agreement about conservative treatment for types I and II ACJ dislocations [5-7], whereas surgical treatment seems to be the best choice for types IV, $\mathrm{V}$ and VI ACJ dislocations [8-11]. Surgical management for acromioclavicular dislocation has been advocated because it restores joint anatomy, thus avoiding obvious 
deformity and a potentially unsatisfactory outcome [12]. However, disadvantages of surgery include migration of pins used for fixation, erosion of the bone by fixation devices, failure of metallic fixation devices, recurrence of deformity, a painful or unsightly scar, late development of acromioclavicular pain and arthritis and a mandatory second operation to remove fixation devices [13]. The advantages of conservative treatment include shorter rehabilitation and sparing hospitalisation [12]. The reported disadvantages of conservative treatment include unsatisfactory results in approximately $20 \%$ of patients due to pain, instability and limitation of motion [14].

The gold standard for the treatment of acute acromioclavicular joint (ACJ) Rockwood type III dislocation is still debated. Most authors obtained good-to-excellent results with nonsurgical management of patients with type III injuries $[5,15,16]$; however, others have reported persistent pain and residual symptoms associated with the acromioclavicular joint at final follow-up evaluations [17-19]. Thus, to improve functional results, some authors advocate surgery for acute type III acromioclavicular joint injuries in young and active patients [20-22]. Moreover, recently, Kirsten et al. reported that in young active patients with type III ACJ dislocation, surgical treatment seems to offer better subjective and cosmetic results than does conservative treatment [23]. The hypothesis of our study was that surgical treatment achieves better results than conservative treatment in athletes between 18 and 35 years old with type III dislocation. This study aimed to compare conservative and surgical treatment of acute type III ACJ injuries in these athletes by analysing clinical and radiological results after a minimum of 24 months follow-up.

\section{Methods}

A retrospective study of patients with acute Rockwood type III acromioclavicular dislocation who were diagnosed and treated at our Orthopaedic Department between January 2006 and December 2011 was performed. Inclusion criteria were age between 18 and 35 years, injury occurred within 21 days [24], absence of concomitant injury or previous surgery and absence of concomitant acromial, coracoid or clavicular fracture. Seventy-two patients met our inclusion criteria, but 17 were lost to follow-up. The remaining 55 patients were categorised into two groups: group A, 25 patients treated conservatively with 4-week immobilisation using a Kenny-Howard brace and group B, 30 patients treated surgically with the TightRope $^{\mathrm{Tm}}$ system (Arthrex, Naples, USA). That system consists of a clavicular round (6.5 $\mathrm{mm}$ in diameter) and an oblong coracoid titanium button $(10 \times 3.5 \mathrm{~mm})$ connected by nonabsorbable No. 5 Fiberwire suture (Arthrex) [25].

After the risks and benefits of conservative or surgical treatment were discussed with the surgeon, the decision between an operative or conservative procedure was made by the patient. Before undergoing treatment, written informed consent was provided by all patients. Both groups of patients underwent clinical and radiological examination at follow-up.

\section{Clinical evaluation}

For the clinical and functional objective evaluation, we used four validated international scales: the University of California Los Angeles shoulder rating scale (UCLA) [26], which analyses pain, range of motion (ROM), function, strength and satisfaction; the American Shoulder and Elbow Surgeons Scale (ASES) [27], which analyses pain and daily life activities; The Constant Score [28], which includes pain, function, $\mathrm{ROM}$ and strength; and the Acromioclavicular Joint Instability Scoring System (ACJI) [25], which includes pain, daily life activities, cosmesis and radiological assessment.

In addition, a subjective evaluation was performed at final follow-up. The patient was asked to a subjectively evaluate the injured shoulder as excellent, good, fair and poor. Moreover, they were asked about their cosmetic subjective satisfaction expressed as highly satisfied, satisfied, poorly satisfied and unsatisfied. Finally, the patient was asked to assign a percentage to the injured shoulder function compared to the contralateral healthy shoulder (Subjective Shoulder Value, SSV).

\section{Radiological evaluation}

The radiological examination consisted of AP and axillary radiographs for each shoulder and bilateral stress radiographs [29]. At the final follow-up visit, an Alexander view radiograph was obtained to calculate the ACJI score as described by Scheibel et al. [25]. The distance between the acromion and lateral clavicle (ACD) and the distance between the coracoid process and clavicle $(\mathrm{CCD})$ were measured (Figure 1). The ACD was measured between the centre of the medial aspect of the acromion and the centre of the lateral aspect of the clavicle. The CCD was measured between the coracoid and inferior cortex of the clavicle [30]. All measurements were performed on the injured and healthy side in stress radiographs at admission (T0) and at the final follow-up visit.

In addition, these parameters were calculated:

- $\Delta$ : the difference in mm between a distance (CCD or ACD) measured at the final follow-up and this distance measured at $\mathrm{T} 0$ in the injured shoulder.

- $\alpha$ : side-to-side difference in $\mathrm{mm}$ of a distance measure at follow-up.

Heterotopic ossification and postoperative osteolysis were also evaluated in both groups [31]. 


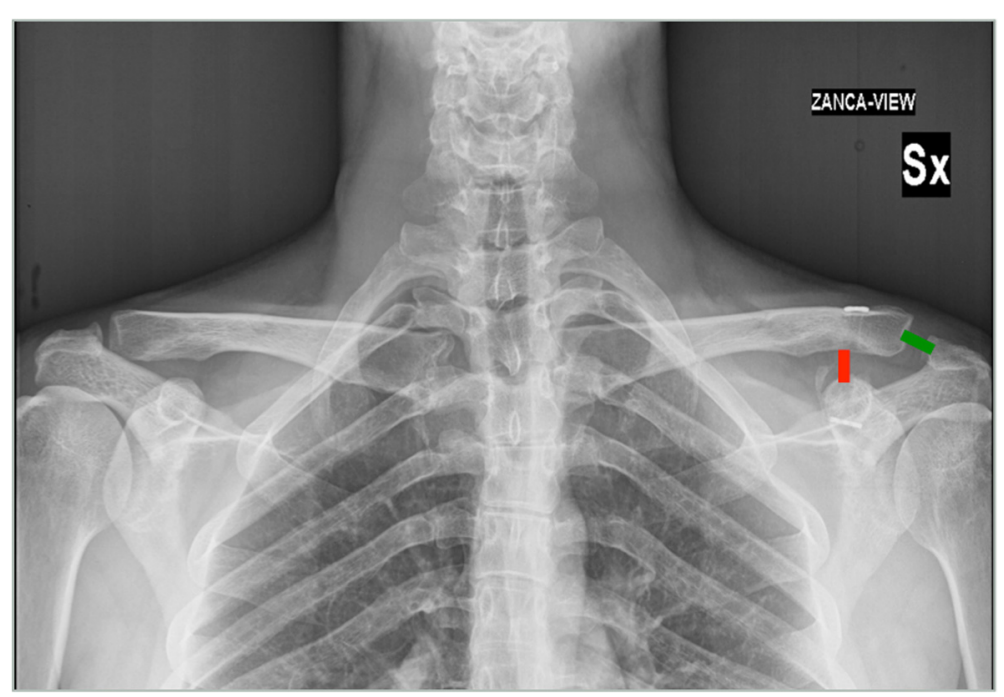

Figure 1 Radiological examination. Green line shows the distance between the acromion and lateral clavicle (ACD); red line shows the distance between the coracoid process and clavicle (CCD).

\section{Surgical treatment}

The mean interval between injury and operation was 7 days (range 0-15 days). General anaesthesia was used in all cases and patients were placed in the "beach-chair" position. An anterior approach was performed in all cases, using a vertical skin incision toward the coracoid tip, starting at the posterior edge of the lateral clavicle (mean scar length, $3.9 \mathrm{~mm}$ ). The fascia of the deltoid muscle was opened along the fibre and the superior part of the distal clavicle and the acromioclavicular joint line were exposed. The base of the coracoid was identified. After exposing the clavicle and coracoid process, a 4$\mathrm{mm}$ hole was drilled into the clavicle approximately $40 \mathrm{~mm}$ from the lateral clavicular edge of the coracoids and into the coracoid base to allow placement of the TightRope. The reduction was performed under visual control. The mean operative time was $42 \mathrm{~min}$ (range, 37-49 $\mathrm{min}$ ).

Postoperatively, the shoulder was protected for 4 weeks using an arm immobiliser sling. However, pendular exercises were commenced within 2 weeks after the first visit. At 4 weeks, passive and active assisted range-ofmotion (ROM), isometric and closed chain exercises were begun. Active exercises through full ROM (ensuring scapula dynamic control) in open chain (below the coronal plane) were started 8 weeks postoperatively. Contact sports and heavy work were permitted after 12 weeks.

\section{Conservative treatment}

The shoulder was placed in a Kenny Howard brace. During the first postoperative days, an ice pack was applied, and mild analgesics were given to the patient. Pendular exercises were permitted after 2 weeks. After 4 weeks, the brace was removed and shoulder motion was progressively increased as symptoms permitted, initially using closed chain exercises and later using active exercises in open chain with the aim of recovering strength and range of motion.

\section{Statistical analysis}

Statistical analysis was performed with SPSS (version 11.5.1). Continuous variables were compared using the Student $t$-test. Results were analysed and the study groups were compared with each other. The chi-square test was used to detect the impact of each procedure. Continuous variable were described using the mean $\pm \mathrm{sd}$. The level of significance was set as $P=0.05$. Illustrations were created using SPSS (version 11.5.1).

\section{Results}

All patients were male with a mean age at the time of this study of 28.7. The mean follow-up time, 3.5 years (range, 2-8 yrs), did not differ significantly between the two groups. All patients were recreational athletes (15 rugby players, 14 soccer players, 5 handball players, 3 basketball players, 4 volleyball players, 9 bikers, and 5 cyclists; the frequency of these sports did not differ by group. Ten patients were sedentary workers, and 20 patients performed light work, 20 performed medium work and 5 heavy work; the frequencies of these work categories were similar between groups.

\section{Clinical evaluation}

The clinical assessment using our validated international scales showed the following results. The mean UCLA 
scores, $33.5 \pm 1.7$ in group A and $34 \pm 0.9$ in group B, were not significantly different, $P>0.05$; the mean Constant scores, $98 \% \pm 3.2$ in group $\mathrm{A}$ and $98.2 \% \pm 2.8$ in group B, were not significantly different, $P>0.05$; and the mean ASES scores, $98.5 \pm 1.6$ in group $A$ and 100 in group $\mathrm{B}$, were not significantly different, $P>0.05$. In contrast, the mean ACJI scores, $72.4 \pm 1.8$ in group A and $87.9 \pm 2.2$ in group $B$, were significantly different, $P<0.05$ (Table 1 ).

The subjective evaluation revealed that $15 \%$ of the conservative treatment group rated their results as excellent, $85 \%$ as good and none as fair or poor. In the surgically treated group, $88 \%$ rated their results as excellent and $12 \%$ as good (Table 2).

When patients were asked to compare the function of the injured shoulder to the contralateral healthy shoulder by assigning a percentage, $37 \%$ of group A patients judged that recovery was $>90$ compared to the healthy side and $63 \%$ assigned a recovery of $70 \%-80 \%$ compared to the contralateral shoulder. In group B, $67 \%$ of patients assigned a recovery $>90 \%$ compared to the healthy side and $33 \%$ assigned a recovery of $70 \%-80 \%$ compared to the contralateral side (Table 3).

Finally, the patient's aesthetic subjective satisfaction was recorded. In group B, 78\% of patients were highly satisfied, $22 \%$ were satisfied and none were poorly satisfied or unsatisfied, whereas in group A, no patients were highly satisfied, only $50 \%$ were satisfied, $30 \%$ were poorly satisfied and 20\% were unsatisfied (Table 4).

\section{Radiological evaluation}

The statistical analysis of our data demonstrated significant differences between the two groups in all measurements (Table 5).

\section{Complications}

None of our patients developed a major complication, but in group B, these minor complications were detected: dislocation of the TightRope in one patient and calcifications in $70 \%$ of patients; all without any clinical correlation. A patient with a superficial wound infection that was treated with antibiotics for a month and healed and two patients with moderate osteolysis were recorded. In group $\mathrm{A}$, calcifications were detected in $30 \%$ of patients

Table 1 Objective evaluation

\begin{tabular}{lll}
\hline & Group A & Group B \\
\hline Constant & $98 \%$ & $98.2 \%$ \\
UCLA & 33.5 & 34 \\
ASES & 98.5 & 100 \\
ACJI & 72.4 & 87.9 \\
\hline
\end{tabular}

Table 1 shows no significant differences in Constant, UCLA and ASES between group A and group B. Significant difference is present in ACJ evaluation in favour of the group $B,(P<0.05)$.
Table 2 Subjective evaluation of the injured shoulder

\begin{tabular}{lll}
\hline & Group A & Group B \\
\hline Poor & - & - \\
Fair & - & - \\
Good & $85 \%$ & $12 \%$ \\
Excellent & $15 \%$ & $88 \%$ \\
\hline Data show better results in patients surgically treated with a significant higher
\end{tabular}

Data show better results in patients surgically treated with a significant higher satisfaction in group $B(P<0.05)$.

and poor satisfaction with cosmetic results in $50 \%$ of patients.

\section{Return to sport activities}

All patients returned to their sport/recreational athletic activities and their work. In group A, $80 \%$ of patients returned to the same level of physical activity as before the injury, whereas $20 \%$ were forced to reduce their activities. In group B, $83 \%$ of patients returned to the same level of physical ability as before the injury, whereas $17 \%$ were forced to reduce their activities. These frequencies did not differ significantly between the two groups (Table 6). Group A returned to sports after a mean of 60 days, whereas group B returned to sports after a mean of 120 days.

\section{Discussion}

The treatment of acute ACJ Rockwood type III dislocation is still debated because of disagreement regarding its optimal management. Moreover, current reviews have identified $>150$ different surgical techniques for its treatment $[32,33]$; in fact, there is still no gold standard for its treatment. Better subjective and radiological results were observed after surgical reduction of ACJ type III dislocation in young active patients. Furthermore, results similar to ours were recently reported by Korsten [23]. Comparison of our data with the international literature is challenging because of few other studies compared surgical and conservative treatment. Moreover, the majority of these reported different surgical techniques using different clinical scales. No differences were found in three objective clinical scales (Constant, ASES and UCLA) between the two groups; however, the ACJI score revealed better results in surgically treated patients. Notably, this scale assigns 35 of 100 points to the radiological evaluation and, in our opinion, uses criteria that are more sensible. Our objective results resemble

Table 3 Function (\%) of injured shoulder compared to the contralateral

\begin{tabular}{lll}
\hline & Group A & Group B \\
\hline $70 \%-80 \%$ & $63 \%$ & $33 \%$ \\
$>90 \%$ & $37 \%$ & $67 \%$ \\
\hline
\end{tabular}

Patients of group $B$ show a better restore of shoulder function than patients of group $A(P<0.05)$. 
Table 4 Patient's aesthetic subjective satisfaction

\begin{tabular}{lll}
\hline & Group A & Group B \\
\hline Unsatisfied & $20 \%$ & - \\
Poorly satisfied & $30 \%$ & - \\
Satisfied & $50 \%$ & $22 \%$ \\
Highly satisfied & - & $78 \%$ \\
\hline
\end{tabular}

Patients of group B show a significant higher satisfaction at the final follow-up than patients of group $\mathrm{A}(P<0.05)$.

those of other studies $[10,31,34]$ even though the objective scales that were used by the other studies often differed from those of our study. The subjective evaluation revealed better results in group B for all subjective clinical scales, including higher satisfaction with cosmetic and functional outcomes in surgically treated patients. Now, the cosmetic outcome is becoming increasingly important. As presented in the above results, the cosmetic outcome, defined as permanent, prominent dislocation of the shoulder, was worse after conservative treatment.

In addition, the radiological evaluation showed better results for CCD and ACD measurements in surgically treated patients. Our results are similar to those of other authors, regardless of the surgical technique. In fact, at the final follow-up, in group B, a significant reductions in CCD and ACD were found, with values similar to the contralateral healthy shoulder and a low rate of complications.

Use of any surgical technique, if compared with conservative treatment, has a higher incidence of complications. In our study, none of our patients developed a major complication, but some minor complications were detected: mobilisation of the TightRope in one patient and coraco-clavicular ligament calcifications in $70 \%$ of patients without corresponding clinical findings. One

\section{Table 5 Radiological results}

\begin{tabular}{llll}
\hline & Group A & Group B & P value \\
\hline ACD injured side T0 & $14.4 \mathrm{~mm} \pm 5.4$ & $14.2 \mathrm{~mm} \pm 1.8$ & - \\
ACD healthy side T0 & $3.9 \mathrm{~mm} \pm 0.9$ & $3.4 \mathrm{~mm} \pm 1.9$ & - \\
CCD injured side T0 & $20.3 \mathrm{~mm} \pm 2.7$ & $21.8 \mathrm{~mm} \pm 3.5$ & - \\
CCD healthy side T0 & $9.9 \mathrm{~mm} \pm 1.6$ & $9.7 \mathrm{~mm} \pm 2.4$ & - \\
ACD T1 & $10.2 \mathrm{~mm} \pm 2.2$ & $4.2 \mathrm{~mm} \pm 1.2$ & - \\
CCD T1 & $16.1 \mathrm{~mm} \pm 0.5$ & $10.4 \mathrm{~mm} \pm 0.2$ & - \\
$\Delta$ ACD & $4.2 \mathrm{~mm}$ & $10 \mathrm{~mm}$ & $<0.05$ \\
$\Delta$ CCD & $4.2 \mathrm{~mm}$ & $11.4 \mathrm{~mm}$ & $<0.05$ \\
a ACD & $6.3 \mathrm{~mm}$ & $0.8 \mathrm{~mm}$ & $<0.05$ \\
a CCD & $6.2 \mathrm{~mm}$ & $0.7 \mathrm{~mm}$ & $<0.05$ \\
\hline
\end{tabular}

This table shows the acromion clavicular distance (ACD) and coraco clavicular distance (CCD) of group A and group B. All the analysed parameters show significant difference in favour of the group $B(P<0.05)$.

$\Delta$ difference between the distance in $\mathrm{mm}$ at the final FU (T1) and T0 in the injured shoulder, $a$ side to side difference in $\mathrm{mm}$ at final $\mathrm{FU}(\mathrm{T} 1)$.
Table 6 Study population

\begin{tabular}{llll}
\hline & Group A & Group B & P value \\
\hline Number & 25 & 30 & n.s. \\
Male/female & $25 / 0$ & $30 / 0$ & n.s. \\
Mean age & 28.5 & 29.2 & n.s. \\
Sport activity level & Recreational & Recreational & n.s. \\
Return to sport & $100 \%$ & $100 \%$ & n.s. \\
& $(80 \%$ same level) & $(83 \%$ same level) & \\
\hline
\end{tabular}

case of infection and two cases with moderate osteolysis of the clavicle were recorded; none of them required revision surgery or hardware removal. In our opinion, surgical reduction during the acute phase with Tightrope could maintain the AC joint reduction during the first months and thereby enable biological healing, by serving work as an "internal brace" that keeps the joint reduced during the necessary healing time. Furthermore, this surgical technique allows visualisation of the achieved reduction, which could explain the low complication rate.

Recently, arthroscopic techniques have emerged and several relevant studies have reported good to excellent clinical and radiological results [35,36]. The major advantage of these arthroscopic procedures is that, if necessary, concomitant shoulder injuries can be detected and addressed at the same time, with minor cosmetic damage. However, complications caused by an incorrect placement of the tunnels in the coracoid process, leading to a dislocation of the Tightrope or a fracture of the coracoid process, have been described [37]. Therefore, this technique is restricted to experienced shoulder arthroscopists [35].

Recently, some authors described a two TightRope arthroscopic technique, using small variations of the TightRope fixing system and introducing anatomic reconstruction with two tunnels. Anatomical two-tunnel reconstruction with tendon grafts or synthetic materials seems appealing because it has been shown by biomechanical studies to restore the strength of the original two ligaments (the conoid and trapezoid), to produce an ultimate failure load that is equivalent to that of native CC ligaments $[38,39]$ and to achieve significantly higher stability in the superoinferior and anteroposterior planes when compared to the native CC ligaments $[36,40,41]$. However, this technique is technically challenging and theoretically increases the risk of fracture [42]. Moreover, authors [35] confirmed that anatomic reconstruction could allow better clinical and radiological results. However, when they performed this technique, they observed a high dislocation rate in the first years. Because this arthroscopic procedure can lead to some difficulties, it is restricted to experienced arthroscopic shoulder surgeons. Our open, nonanatomic technique seems to be a simpler procedure that affords immediate visual control of the hole placement and joint reduction. Of note, several prior studies reported 
results of using the TightRope system in both acute and chronic patients for higher levels of dislocations than type III [43-45]. In contrast, a more uniform patient mix with respect to the type of dislocation and the timing of the intervention was included in our study. The results of the functional shoulder evaluation score did not differ significantly by treatment group except for the score that combines radiographic and subjective outcomes, the ACJI. Although it is not possible to state that surgically treated patients reported a better result, the high percentage of unsatisfied patients among those who were treated conservatively merits consideration. In fact, patients in the conservative group had high scores in the scales and early recovery of the sport activities, comparable to the surgical group; however, at the final follow-up, they reported a constantly present discomfort in the injured side. The scale for the sick scapula syndrome, presented by Kibler et al. [46] and Burkart et al. [47] and analysed by Gumina [48], could explain, as did the ACJI [25], this difference between the groups. Unfortunately, this scale was not analysed in our study.

Our study has some limitations. Most notable, it is a retrospective study with the biases inherent to this kind of design. Moreover, the surgical solution is more expensive than the conservative treatment and our study lacks cost analysis. Because the results of our study indicate distinct advantages of both treatment approaches, it is challenging to make definitive recommendations. Both the conservative and surgical treatments seem to offer excellent clinical results. The more rapid return to athletic activities following conservative treatment is a clear, short-term advantage of the conservative approach. However, the patient who chooses conservative treatment should be informed that in the future, he could feel a difference in the injured shoulder, which could lead to dissatisfaction with the conservative treatment.

\section{Conclusions}

This retrospective comparison of conservative and surgical treatment for type III acromioclavicular joint dislocation shows better subjective and radiographic results for the surgically treated group. However, the objective outcome scores do not indicate significant differences between the two groups. Therefore, treatment options should be thoroughly discussed with patients, weighing all subjective, objective and radiographic outcomes and the relative advantages of each option.

\section{Competing interests}

The authors declare that they have no competing interests.

\section{Authors' contributions}

ADC had substantial contributions to analysis and interpretation of data. RML had substantial contributions to conception and design of the study. AC had been involved in revising the manuscript. DL agree to be accountable for all aspects of the work in ensuring that questions related to the accuracy or integrity of any part of the work are appropriately investigated and resolved.
PR had substantial contributions to acquisition of data. AF have given final approval of the version to be published. All authors read and approved the final manuscript.

Received: 17 September 2014 Accepted: 30 December 2014

Published online: 28 January 2015

\section{References}

1. Bishop JY, Kaeding C. Treatment of the acute traumatic acromioclavicular separation. Sports Med Arthrosc. 2006;14(4):237-45.

2. Kaplan LD, Flanigan DC, Norwig J, Jost P, Bradley J. Prevalence and variance of shoulder injuries in elite collegiate football players. Am J Sports Med. 2005;33(8):1142-6.

3. Kelly BT, Barnes RP, Powell JW, Warren RF. Shoulder injuries to quarterbacks in the national football league. Am J Sports Med. 2004;32(2):328-31.

4. Jacobs B, Wade PA. Acromioclavicular-joint injury. An end-result study. J Bone Joint Surg Am. 1966;48(3):475-86.

5. Rolf O, Hann von Weyhern A, Ewers A, Boehm TD, Gohlke F. Acromioclavicular dislocation Rockwood III-V: results of early versus delayed surgical treatment. Arch Orthop Trauma Surg. 2008;128(10):1153-7.

6. Hootman JM. Acromioclavicular dislocation: conservative or surgical therapy. J Athl Train. 2004;39(1):10-1.

7. Bannister GC, Wallace WA, Stableforth PG, Hutson MA. The management of acute acromioclavicular dislocation. A randomised prospective controlled trial. J Bone Joint Surg (Br). 1989;71(5):848-50.

8. Tauber M. Management of acute acromioclavicular joint dislocations: current concepts. Arch Orthop Trauma Surg. 2013;133(7):985-95.

9. Rockwood C, Green D, Bucholz R, Heckman J. Fractures in adults, vol 1 ed, 4th edn. Philadelphia: Lippincott-Raven; 1341-1413

10. Prokop A, Helling HJ, Andermahr J, Mönig S, Rehm KE. Tossy III injuries of the acromioclavicular joint. In what circumstances is surgery still justified? Personal results and literature review. Orthopade. 2003;32(5):432-6. German. PubMed PMID: 12743695.

11. Weaver JK, Dunn HK. Treatment of acromioclavicular injuries, especially complete acromioclavicular separation. J Bone Joint Surg Am. 1972:54(6):1187-94.

12. Rawes ML, Dias JJ. Long-term results of conservative treatment for acromioclavicular dislocation. J Bone Joint Surg (Br). 1996;78(3):410-2.

13. Galatz LM, Williams Jr GR. Acromioclavicular Joint Injuries. In: Bucholz RW, Heckman JD, Court-Brown CM, editors. Rockwood \& Green's Fractures in Adults, vol. 2. 6th ed. Philadelphia: Lippincott Williams \& Wilkins; 2005. p. 1332-64.

14. Kennedy JC, Cameron H. Complete dislocation of the acromio-clavicular joint. J Bone Joint Surg (Br). 1954;36-B(2):202-8.

15. Bjerneld H, Hovelius L, Thorling J. Acromio-clavicular separations treated conservatively. A 5-year follow-up study. Acta Orthop Scand. 1983;54(5):743-5.

16. Taft TN, Wilson FC, Oglesby JW. Dislocation of the acromioclavicular joint. An end-result study. J Bone Joint Surg Am. 1987:69(7):1045-51.

17. Mouhsine E, Garofalo R, Crevoisier X, Farron A. Grade I and II acromioclavicular dislocations: results of conservative treatment. J Shoulder Elbow Surg. 2003;12(6):599-602.

18. Schlegel TF, Burks RT, Marcus RL, Dunn HK. A prospective evaluation of untreated acute grade III acromioclavicular separations. Am J Sports Med. 2001;29(6):699-703.

19. Wojtys EM, Nelson G. Conservative treatment of Grade III acromioclavicular dislocations. Clin Orthop Relat Res. 1991;268:112-9.

20. Ryhänen J, Niemelä E, Kaarela O, Raatikainen T. Stabilization of acute, complete acromioclavicular joint dislocations with a new C hook implant. J Shoulder Elbow Surg. 2003;12(5):442-5.

21. Gstettner C, Tauber M, Hitzl W, Resch H. Rockwood type III acromioclavicular dislocation: surgical versus conservative treatment. J Shoulder Elbow Surg. 2008;17(2):220-5.

22. Lizaur A, Sanz-Reig J, Gonzalez-Parreño S. Long-term results of the surgical treatment of type III acromioclavicular dislocations: an update of a previous report. J Bone Joint Surg (Br). 2011;93(8):1088-92.

23. Korsten K, Gunning AC, Leenen LP. Operative or conservative treatment in patients with Rockwood type III acromioclavicular dislocation: a systematic review and update of current literature. Int Orthop. 2014;38(4):831-8.

24. Flint JH, Wade AM, Giuliani J, Rue JP. Defining the terms acute and chronic in orthopaedic sports injuries: a systematic review. Am J Sports Med. 2014;42(1):235-41.

25. Scheibel M, Dröschel S, Gerhardt C, Kraus N. Arthroscopically assisted stabilization of acute high-grade acromioclavicular joint separations. Am J 
Sports Med. 2011;39(7):1507-16. doi:10.1177/0363546511399379. Epub 2011 Mar 24.

26. Amstutz HC, Sew Hoy AL, Clarke IC. UCLA anatomic total shoulder arthroplasty. Clin Orthop Relat Res. 1981;Suppl 155:7-20.

27. Richards RR, An KN, Bigliani LU, Friedman RJ, Gartsman GM, Gristina AG, et al. A standardized method for the assessment of shoulder function. J Shoulder Elbow Surg. 1994;3(6):347-52.

28. Constant CR, Murley AH. A clinical method of functional assessment of the shoulder. Clin Orthop Relat Res. 1987;214:160-4.

29. Zanca P. Shoulder pain: involvement of the acromioclavicular joint. (Analysis of 1,000 cases). Am J Roentgenol Radium Ther Nucl Med. 1971;112(3):493-506.

30. Horst K, Dienstknecht T, Andruszkow H, Gradl G, Kobbe P, Pape HC. Radiographic changes in the operative treatment of acute acromioclavicular joint dislocation -tight rope technique vs. K-wire fixation. Pol J Radiol. 2013;78(4):15-20.

31. Calvo E, López-Franco M, Arribas IM. Clinical and radiologic outcomes of surgical and conservative treatment of type III acromioclavicular joint injury. J Shoulder Elbow Surg. 2006;15(3):300-5.

32. Beitzel K, Obopilwe E, Apostolakos J, Cote MP, Russell RP, Charette R, et al. Rotational and translational stability of different methods for direct acromioclavicular ligament repair in anatomic acromioclavicular joint reconstruction. Am J Sports Med. 2014;42(9):2141-8.

33. Beitzel $\mathrm{K}$, Cote MP, Apostolakos J, Solovyova O, Judson CH, Ziegler CG, et al. Current concepts in the treatment of acromioclavicular joint dislocations. Arthroscopy. 2013;29(2):387-97.

34. Esen E, Özturk A, Doğramaci Y, Kanatli U, Bölökbași S. Comparison of surgical treatment and conservative approach for type III acromioclavicular dislocations. Turkiye Klinikleri J Med Sci. 2011;31(1):109-14.

35. Salzmann GM, Walz L, Buchmann S, Glabgly P, Venjakob A, Imhoff AB. Arthroscopically assisted 2-bundle anatomical reduction of acute acromioclavicular joint separations. Am J Sports Med. 2010;38(6):1179-87.

36. Walz L, Salzmann GM, Fabbro T, Eichhorn S, Imhoff AB. The anatomic reconstruction of acromioclavicular joint dislocations using 2 TightRope devices: a biomechanical study. Am J Sports Med. 2008;36(12):2398-406.

37. Gerhardt DC, VanDerWerf JD, Rylander LS, McCarty EC. Postoperative coracoid fracture after transcoracoid acromioclavicular joint reconstruction. J Shoulder Elbow Surg. 2011;20(5):e6-10.

38. Costic RS, Labriola JE, Rodosky MW, Debski RE. Biomechanical rationale for development of anatomical reconstructions of coracoclavicular ligaments after complete acromioclavicular joint dislocations. Am J Sports Med. 2004;32(8):1929-36.

39. Mazzocca AD, Santangelo SA, Johnson ST, Rios CG, Dumonski ML, Arciero RA. A biomechanical evaluation of an anatomical coracoclavicular ligament reconstruction. Am J Sports Med. 2006;34(2):236-46.

40. Jones HP, Lemos MJ, Schepsis AA. Salvage of failed acromioclavicular joint reconstruction using autogenous semitendinosus tendon from the knee. Surgical technique and case report. Am J Sports Med. 2001;29(2):234-7.

41. Lee SJ, Nicholas SJ, Akizuki KH, McHugh MP, Kremenic IJ, Ben-Avi S. Reconstruction of the coracoclavicular ligaments with tendon grafts: a comparative biomechanical study. Am J Sports Med. 2003;31(5):648-55.

42. Yoo JC, Ahn JH, Yoon JR, Yang JH. Clinical results of single-tunnel coracoclavicular ligament reconstruction using autogenous semitendinosus tendon. Am I Sports Med. 2010;38(5):950-7.

43. Motta P, Maderni A, Bruno L, Mariotti U. Suture rupture in acromioclavicular joint dislocations treated with flip buttons. Arthroscopy. 2011;27(2):294-8.

44. Somers JF, Van der Linden D. Arthroscopic fixation of type III acromioclavicular dislocations. Acta Orthop Belg. 2007;73(5):566-70.

45. El Sallakh SA. Evaluation of arthroscopic stabilization of acute acromioclavicular joint dislocation using the TightRope system. Orthopedics. 2012;35(1):e18-22.

46. Kibler WB, Uhl TL, Maddux JW, Brooks PV, Zeller B, McMullen J. Qualitative clinical evaluation of scapular dysfunction: a reliability study. J Shoulder Elbow Surg. 2002;1 1(6):550-6.

47. Burkhart SS, Morgan CD, Kibler WB. The disabled throwing shoulder: spectrum of pathology Part III: The SICK scapula, scapular dyskinesis, the kinetic chain, and rehabilitation. Arthroscopy. 2003;19(6):641-61. Review.

48. Gumina S, Carbone S, Postacchini F. Scapular dyskinesis and SICK scapula syndrome in patients with chronic type III acromioclavicular dislocation. Arthroscopy. 2009;25(1):40-5.

\section{Submit your next manuscript to BioMed Central and take full advantage of:}

- Convenient online submission

- Thorough peer review

- No space constraints or color figure charges

- Immediate publication on acceptance

- Inclusion in PubMed, CAS, Scopus and Google Scholar

- Research which is freely available for redistribution

Submit your manuscript at www.biomedcentral.com/submit 